\title{
LAS LEYES DE RESCINDENDA VENDITIONEY LA CONFIGURACIÓN ORIGINARIA DE LA RESCISIÓN DEL CONTRATO POR LESIÓN ENORME*
}

The laws "De rescindenda venditione" and the original configuration of the rescission of the contracts because of laesio enormes

Nathalie Walker Silva**

UNIVERSIDAD ADOLFO IBÁÑEZ

SANTIAGO, Chile

Una versión abreviada de este estudio fue presentada en el Congreso Mundial de Derecho Romano y Comparado, que tuvo lugar en la Facultad de Derecho de la Pontificia Universidad Católica de Valparaíso el 23 y 24 de julio de 2015. A su vez una versión corregida y aumentada del mismo, fue incorporada en mi tesis doctoral "Rescisión por lesión en el Código Civil chileno", para optar al grado de Doctor en Derecho por la Pontificia Universidad Católica de Chile.

* Doctora en Derecho por la Pontificia Universidad Católica de Chile. Académica investigadora, Universidad Adolfo Ibáñez. Correo electrónico: <nathalie.walker@edu.uai.cl>.

Artículo recibido el 25 de agosto de 2017 y aceptado para publicación el 8 de noviembre de 2017. 
RESUMEN: Las fuentes romanas en materia de compraventa e ineficacia de los contratos no contienen una teoría de la rescisión con bases sólidas, sino que resuelven casos aislados y contradictorios entre sí. El genuino principio sancionador de la lesión enorme recién comienza a perfilarse en la obra justinianea, gracias a la generalización del contenido de los textos recogidos en la rúbrica De rescindenda venditione. De modo que el Corpus luris no se limita a recoger una teoría suficientemente perfilada y autónoma, sino que su concreta contribución es la de haber sentado las bases para una posterior expansión y perfeccionamiento de la doctrina incorporada en el Codex, que irá de la mano del concepto medieval de laesio enormis.

PALABRAS CLAVE: rescindenda venditione, laesio enormis, rescisión del contrato.

ABSTRACT: The Roman sources in matters of purchase and ineffectiveness of contracts do not contain a theory of rescission with solid foundations, but rather resolve insolated cases and cases contradictory among themselves. The genuine sanctioning principle of laesio enormis has just begun to be outlined in the work justinian, because of the generalization of the content of the texts collected in the rubric "De rescindenda venditione". So the Corpus luris does not limit itself to collecting a sufficiently profiled and autonomous theory, but its concrete contribution is to have laid the foundations for a further expansion and improvement of the doctrine incorporated in the Codex, which will go together with the medieval concept of laesio enormis.

KEYWORDS: rescindenda venditione, laesio enormis, rescission of the contract. 


\section{INTRODUCCIÓN}

Existe una abundante literatura sobre la rescisión por lesión y, pese a ello, pocos autores disienten acerca de que el origen de esta institución se encuentre en las Leyes de rescindenda venditione, dos rescriptos imperiales atribuidos a DIOCLECIANO y MAXIMIANO que fueron incorporados en el corpus iuris civilis de Justiniano. La discusión gira, más bien, en torno a la autenticidad de esos rescriptos, ya que no está claro si el texto que aparece en el corpus iuris es un texto clásico, si es original de la época en que fueron dictados, o si contendría ciertos aditamentos incorporados por quienes participaron en la labor compiladora justinianea o por copistas de ediciones posteriores. Aunque también hay autores que afirman que la rescisión por lesión tiene un punto de partida aún más remoto que los rescriptos ya citados ${ }^{1}$ y otros pocos que creen que el origen del principio sancionador de la lesión enorme es posterior a la datación de aquéllos².

\section{LAS LEYES 2 Y 8, DE RESCINDENDA VENDITIONE (C. 4. 44)}

En el Código del Corpus luris se encuentra la famosa "lex Secunda", tantas veces postulada por la doctrina como antecedente remoto de la moderna rescisión por lesión ultra dimidium. Si bien es cierto que la posibilidad de rescindir un contrato por lesión está incorporada en dos rescriptos atribuidos a los emperadores DIOCLECIANO y MAXIMIANO -tratados conjuntamente bajo el título de Leyes de rescindenda venditione-, es el primero de ellos (la lex Secunda) el que tiene un contenido más determinante y, por lo mismo, ha pasado a la historia como el hito inicial que moldea el principio sancionador de la rescisión por lesión enorme.

Las Leyes de rescindenda venditione ("Sobre la rescisión de la venta") son rescriptos imperiales. Es decir, son respuestas dadas por el emperador a

1 Dentro de los antecedentes más remotos que se han postulado en torno a la rescisión, se encuentra incluso el Código de Hammurabi, que en algunos párrafos efectúa ciertas declaraciones de justicia, así como cláusulas sobre intereses usurarios y regulación sobre precios máximos para algunos bienes y servicios. MARTín (1995) pp. 79 y 80.

$2 \quad$ Vid., por todos: D’Ors (2004) p. 581, quien afirma: “Todavía en 244 d.C. (C.J. 8.40.18) el justo precio es irrelevante, pero Justiniano estableció para la venta de inmuebles la facultad de rescindir la venta por injusticia del precio, debiéndose entender por injusto el precio cuando es inferior a la mitad del valor verdadero del inmueble".

3 Accursio la refiere como: "ista est famosa lex". Corpus IURIS Civilis cum glossis Accursil (2006) columna 1013. 
un problema jurídico de un particular4. Es así como en la Ley Segunda aparece de manifiesto que DiocleCIANO y Maximiano dan respuesta a una consulta planteada por Aurelio Lupo. La Ley Octava, en cambio, va dirigida a Evodia. El primero de los rescriptos - Ley Segunda- aparece fechado en el año 285 d.C, Mientras que la Ley Octava, dataría del año 293 d.C.

El texto de la Ley Segunda, cuyo conocimiento ha llegado hasta nosotros mediante el Corpus luris Civilis, es el siguiente: C. 4. 44, 2 Impp. Diocletianus et Maximianus AA. Lupo: "Rem majoris pretii si tu vel pater tuus minoris distraxerit, humanum est, ut vel pretium te restituente emptoribus fundum venundatum recipias, auctoritate judicis intercedente: vel, si emptor elegerit quod deest iusto pretio recipias. Minus autem pretium esse videtur, si nec dimidia pars [veri] pretii soluta sit"s.

De la críptica formulación de la lex Secunda pueden extraerse algunos principios con los que ha trabajado la doctrina hasta el día de hoy. El primero nos indica que es posible dejar sin efecto la venta de una cosa (rem), específicamente un inmueble (fundus), cuando ha sido vendido a un precio inferior al justo; el segundo hace énfasis en el fundamento equitativo de la institución (humanum est) y que ésta opera sólo a través de una sentencia judicial (auctoritate iudicis); el tercero incorpora la posibilidad de mantener vigente el contrato si el comprador satisface el suplemento del precio (iusto pretio); y el cuarto principio dispone que el remedio sólo se hará aplicable cuando el precio pagado por el comprador sea inferior a la mitad del valor de la cosa vendida (minus autem pretium esse videtur, si nec dimidia pars veri pretii soluta sit).

Por su parte, el texto de la Ley Octava es el siguiente:

C. 4, 44, 8 Impp. Diocletianus et Maximianus AA. et CC. Aureliae Euodiae: "Si voluntate tua fundum tuum filius tuus venumdedit: dolus et calliditate atque insidiis emptoris argui debet, vel metus

4 Burke (1830) pp. 223 y 224, y Bueno (2013) p. 382. Según Ciapparoni (1968) p. 587: “Para la doctrina jurídica intermedia, el rescripto es una fuente normativa, a veces de un alcance muy particular, expresión de la voluntad soberana directa a la solución de un caso concreto".

5 Corpus IUris Civilis cum glossis Accursil (2006), columnas 1014 y 1015. Su traducción al castellano es: "Si tú o tu padre hubiereis vendido a un precio menor una cosa de mayor precio, es humano que, o restituyendo tú el precio a los compradores, recobres el fundo mediante la autoridad del juez; o bien, si el comprador lo prefiere, recibas tú lo que falta para el precio justo. Parece ser precio menor, si no se ha pagado ni la mitad del precio verdadero". 
mortis, vel cruciatus corporis imminens detegui, ne habeatur rata venditio. Hoc enim solum, quod paulo minori pretio fundum venditum significans, ad rescindendam venditionem invalidum est. Quod si videlicet contractus emtionis atque venditionis cogitasses substantiam, et quod emptor viliore comparandi, venditor cariori distrahendi votum gerentes, ad hunc contractum accedant, vixque post multas contentiones, paulatim venditore de eo quod petierat detrahente, emptore autem huic quod obtulerat, addente, ad certum consentiant pretium: profecto perspiceres, neque bonam fidem, quae emptionis atque venditionis conventionem tuetur, pati neque ullam rationem concedere, rescindi propter hoc consensu finitum contractum, vel statim, vel post pretii quantitatis disceptationem; nisi minus dimidia iusti pretii, quod fuerat tempore venditionis, datum est, electione iam emptori praestita servanda"6.

El caso planteado por Aurelio Evodia puede resumirse en estos términos: el hijo de Evodia vendió un fundo -con la autorización de este último- por un precio algo menor y lo que se pretende es rescindir el contrato. Al problema expuesto, la respuesta de los emperadores es clara: para rescindir la venta no basta haber vendido a un precio paulo minore -poco menor-; es preciso, además, haber sufrido dolo o miedo. En esto se aparta de la Ley Segunda, la cual no exige un elemento subjetivo para la rescisión, pero sí se asemeja a ella en cuanto establece un límite al desequilibrio en las prestaciones en su

$6 \quad$ El contenido de la Ley Octava puede traducirse de esta forma: "Si tu hijo -con tu consentimiento- ha vendido tu fundo, para obtener la nulidad de la venta deberás justificar el dolo resultante de los artificios y acechanzas del adquirente, o la amenaza de tormentos corporales, y aun de muerte, que empleó para obligarle a celebrar el contrato. Por ello, el solo motivo de que alegaras que el fundo no se vendió por su justo valor, no bastaría para hacer rescindir la venta. En efecto, si atiendes a la naturaleza del contrato de venta; si consideras que el comprador trata de comprar al menor precio posible, y que el vendedor desea obtener la mayor ganancia posible, y que no llegan a entenderse ni a ajustar su contrato sino después de muchas discusiones; el vendedor disminuyendo poco a poco el primitivo precio, y el comprador, por su parte, añadiendo algo a lo primeramente ofrecido, y que al fin convienen en un precio; comprenderás, entonces, que ni la buena fe -que es la esencia del contrato de venta-, ni ninguna otra razón permite que se te conceda por este solo motivo la rescisión de un contrato terminado por consentimiento mutuo, a menos que se te hubiese dado un precio menor a la mitad del valor del fundo cuando tuvo lugar la venta, debiéndose en tal caso conceder al comprador la elección arriba ofrecida". Corpus Iuris Civilis cum glossis Accursil (2006), columnas 1017 y 1018. 
parte final, en la frase: "a no ser que se te hubiese dado un precio menor a la mitad del valor del fundo cuando tuvo lugar la venta".

Nótese la diferencia entre las expresiones empleadas en ambos textos para referirse al precio de la venta. La Ley Segunda, en su caso, se refiere a dos nociones distintas: la de "precio justo" y la de "precio verdadero"; la Ley Octava, en cambio, sólo hace mención al justo precio y no al verum pretium.

Esta divergencia ha sido analizada por RAsCón, quien advierte que las expresiones verum pretium iustum pretium no son sinónimas. En opinión de este autor: "en C. 4.44.2 se emplean las locuciones iustum pretium y verum pretium, expresión ésta última que, con toda probabilidad, hace referencia al precio de mercado. Sin embargo, en C. 4.44 .8 se dice siempre iustum pretium. Tal vez sea este un indicio de que la primera de las constituciones no está interpolada, en la medida en que en ella el problema todavía no había salido del ámbito jurídico, aunque se trate de una solución imperial basada en la equidad, como se refleja en su fundamentación (humanum est). Por el contrario, en la segunda constitución, el problema se plantea en el ámbito de la justicia como cuestión moral, fruto, una vez más, de la influencia cristiana"7. Para RAsCón: "el justo precio comporta la necesidad de acudir a criterios morales para su determinación. Precio justo no es el ajustado a Derecho, sino el que no rompe la regla de la equidad que debe presidir los contratos conmutativos, la cual se debe manifestar en la equivalencia de las prestaciones $^{\prime \prime}$. Así, siguiendo este razonamiento, la clave del problema de la rescisión por lesión, desde un punto de vista práctico, se encontraría en la determinación de la equivalencia de las prestaciones y, en última instancia, del justo precio's.

Como puede anticiparse de este breve examen preliminar, las leyes Segunda y Octava han generado diversas discusiones doctrinarias -muchas de las cuales aún se encuentran en desarrollo ${ }^{10}$ - tanto acerca de la autenticidad de su contenido, de sus aspectos formales y de la aplicación práctica a que habrían dado lugar. Para efectos del objeto de esta investigación, nos ocuparemos de las siguientes: 1. La disputa en torno a la interpolación de los textos; 2 . La clase de objetos a los que se aplica el remedio rescisorio; 3. Los sujetos que resultan beneficiados; 4 . El tipo de contratos que pueden

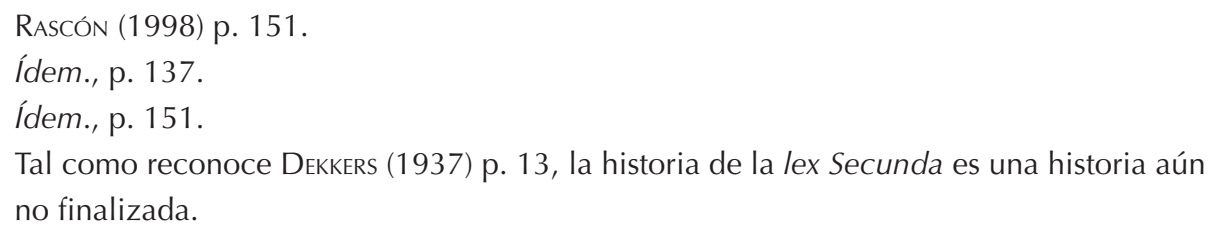


rescindirse y el procedimiento aplicable y, por último, 5. La referencia de los textos a las razones de justicia y equidad.

\section{EL PROBLEMA DE LAS INTERPOLACIONES}

Uno de los debates más arduos que se han generado en torno a los rescriptos imperiales citados, se suscita en torno a la posibilidad de que ambos hayan sido interpolados por los compiladores del Corpus luris Civilis de JUSTINIANO. En efecto, muchos autores han afirmado que, producto de las correcciones, adaptaciones y sucesivas ediciones del Corpus luris, los textos originales de esta obra fueron modificados o adulterados, dando lugar a pasajes espurios. Desde luego, no ha escapado a este debate lo concerniente a las Leyes De rescindenda venditione ${ }^{11}$.

Sabemos hoy en día que las comisiones del Código y del Digesto contaron con la autorización de JUSTINIANO para suprimir, corregir y completar los textos auténticos, entregando una visión de conjunto que se aleja de los cánones utilizados en el Derecho clásico ${ }^{12}$. En tal sentido se ha planteado que "las alteraciones introducidas por JUSTINIANO representan algo más profundo que un accidente editorial: constituyen todo un trabajo sistemático de correcciones y adaptaciones que significó, en cierta manera, una total reelaboración del Derecho clásico sobre criterios postclásicos ${ }^{\prime 13}$. Con ello se pretendía perfeccionar el material compilado, evitar las contradicciones presentes entre los juristas del pasado y, también, desechar instituciones anticuadas que no se adaptaban del todo bien a la realidad social del mundo bizantino ${ }^{14}$.

Si bien es cierto que la Ciencia Jurídica oriental debió encontrarse en un grado de desarrollo bastante alto para haber dado origen a una obra tan vasta en tan corto tiempo ${ }^{15}$, muchas de las dudas y misterios que suscitó la génesis

11 En opinión de Montaña (1999) p. 38, "desde Gradenwitz hasta la mitad del presente siglo [se refiere al pasado siglo XX], la doctrina se ha decantado casi unánimemente por la tesis de la no autenticidad del texto, en ocasiones siguiendo la corriente interpolacionista del momento, mientras una serie de estudios de los últimos años, abandonando los formalismos de la crítica de interpolaciones, analiza la cuestión desde una perspectiva más amplia, llegándose en ocasiones, por parte de alguno de estos autores, a afirmar la autenticidad del texto u optando por posturas intermedias".

12 Kunkel (1972) pp. 179-180, SAMPer (2007) p. 58.

13 SAMPER (2007) p. 58.

14 Kunkel (1972) p. 180, Amunátegul (2011) p. 237.

15 Honoré (2004) pp. 3-5. Así, por ejemplo, el Digesto se promulgó en diciembre del año 534, sólo seis años después de asumir JustinIANO como emperador. 
del Corpus luris aún no se han dilucidado. Al respecto, es importante considerar que el propio JUSTINIANO afirmó que la comisión redactora debió revisar más de tres mil libros, lo que comprende una masa enorme de material, difícilmente asimilable en ese breve intervalo de tiempo ${ }^{16}$.

La relación inversa entre la gran calidad del resultado final y el poco tiempo empleado en la redacción del Corpus luris es un tema pendiente para los romanistas y que, sin duda, ha impulsado con fuerza la tesis de las interpolaciones. Esta última ha sido una de las cuestiones más apremiantes para la romanística del siglo XX y la pregunta básica que la sustenta es cuánto del Digesto corresponde al Derecho Romano clásico y cuánto a alteraciones justinianeas ${ }^{17}$. Es este un tema nada pacífico en doctrina y-como suele ocurrir en el análisis de las fuentes romanas- nadie se encuentra en condiciones de afirmar algo con absoluta certeza.

En el ámbito que aquí nos ocupa, la doctrina se ha posicionado en tres líneas fundamentales de investigación -aunque no las únicas- ${ }^{18}$ : 1 . Quienes legitiman la autoría de DiocleCiAnO y Maximiano y la validez uniforme del instituto hasta JustINIANO ${ }^{19} ; 2$. Los que afirman que fue un instituto introducido por DIOCLECIANO para casos excepcionales, cayendo en el olvido en siglos sucesivos hasta su aceptación por parte de los compiladores del siglo VI d.C. ${ }^{20}$, y 3. Los que piensan que la rescisión por lesión enorme fue una innovación típicamente justinianea ${ }^{21}$, siendo desconocida en tiempos de DıOCLECIANO ${ }^{22}$.

El primer autor que se pronunció acerca de la eventual falta de autenticidad de las leyes de rescindenda venditione -0 , al menos, del que se tiene registro- fue Christian ThOMAsIus, en el siglo XVIII. En su disertación,

\footnotetext{
16 Amunátegui (2011) p. 236.

17 Kunkel (1972) pp. 179-18, Zimmermann (2010), pp. 43-46, y Amunátegui (2011) p. 236.

18 Hay también algunas que podríamos denominar "de corte escéptico", por cuanto se plantean la duda acerca de la autenticidad de los rescriptos, pero no se pronuncian de modo categórico. En este grupo encontramos, por ejemplo, a WATSON (1981) p. 186, y ZIMMERMANN (1990) p. 259.

19 Es la teoría sustentada por todos los autores anteriores a THOmasius y aquellos que publican su obra después de De aequitate cerebrina (1706) hasta Gradenwitz (1889). Vid., por todos, Aquino (2008) pp. 302-304.

20 Vid., por todos, VISKY (1961) pp. 61 y 62.

21 Es, por ejemplo, la opinión de Gradenwitz (1889) pp. 14-15, Girard (1929) p. 575, y

D'Ors (2004) p. 581

22 PARRA (2008) p. 4.
} 
denominada "De aequitate cerebrina" 23 , el autor deja en evidencia la contradicción existente entre la lex secunda y otras leyes emanadas de DıOCLECIANO, que negaban lugar a la rescisión por laesio ultra dimidium ${ }^{24}$.

Un siglo más tarde, GradenWITZ ${ }^{25}$ retoma la crítica a los rescriptos y postula categóricamente la interpolación de la lex Secunda. Para ello se basa, fundamentalmente, en la ausencia de textos jurídicos posteriores a DıOCLECIANO que sancionen la existencia de lesión en el precio, como por ejemplo en el Código Teodosiano ${ }^{26}$. Esta ausencia de continuidad en la regulación, además

23 La expresión cerebrina da la idea de un uso artificioso o caprichoso de la equidad. Es por eso que Chamie (2010) p. 24, traduce el término por "equidad bizantina"; nosotros diríamos "imaginaria".

24 Señala Thomasius (1730) p. 44: "Sed et quod versiculus ultimus legis sit quali instar glossae extra sensum legis \& contextus positus [...]. Collectores vero iuris lustinianei, humanitati illa cerebrina prioris rescripti semel inescati, cum posterius Diocletiani rescriptum viderent cum priori non bene convenire, putarunt distinctione illa inter minus dimidio \& dimidio non minus duo ista rescripta conciliare posse, atque sic utrobique additis versiculis finalibus leges illas Diocletiani interpolarunt". Trad.: "Con todo, que el último reglón de la ley sea casi parecido al sentido y al nexo de la ley establecido fuera de la glosa [...]. Pues los compiladores del derecho de Justiniano, una vez atraídos por aquella imaginaria humanidad, después de que vieron más tarde el rescripto de Diocleciano, ya que no estaban de acuerdo con el primero, pensaron en aquella distinción entre menos de la mitad y no menos de la mitad para poder conciliar los dos rescriptos, de este modo la añadieron en uno de los reglones finales que interpolaron en aquellas leyes de Diocleciano". Efectivamente, existe la contradicción que advierte Thomasius en el contenido de la lex Secunda con otros rescriptos de los mismos emperadores. Para demostrarla puede citarse, a modo ejemplar: D.4.44.4 Impp. Diocletianus et Maximianus AA. et CC. Sempronio Euxodio: "Ad rescindendam venditionem et malae fidei probationem hoc solum non sufficit, quod magno pretio fundum comparatium minoris distractum esse conmemoras D. Non April Byzantio AA. conss.". En este rescripto, los emperadores dan respuesta a Euxodio, quien alega que vendió un fundo a un precio menor del que, en su momento, lo compró; le indican que la mala fe que alega y que correspondería a la diferencia de ambos precios, no es razón suficiente para que pueda rescindir el contrato.

25 Gradenwitz (1889) pp. 14 y 15.

26 El Código Teodosiano es una recopilación de todas las Constituciones imperiales desde la época de Constantino. Fue concluido en el año 438 y publicado como Código para el imperio de Oriente. Parte de su importancia radica en la influencia que tuvo en el origen de algunas instituciones medievales. PARrA (2008) p. 3. Los fragmentos del Código que se relacionan con el tema en comento son los que a continuación se exponen, tomados de Codex Theodosianus (1905): C.Th. 3.1.1: Imp. Constantinus A. ad profuturum praefectum annonae: "Venditionis atque emptionis fidem nulla circumscriptionis violentia facta rumpi 
de otros problemas de interpretación que suscitan los textos, hacen dudar a este autor de que la rescisión por lesión sea obra de DıOCLECIANO. A esta opinión se suman también las de AlberTaRIO ${ }^{27}$, SOlazZI ${ }^{28}$, DeKKERS ${ }^{29}$ y varios otros autores de la tendencia denominada "hipercrítica" que, en síntesis, afirma que la mayoría de los textos del Corpus luris están interpolados. En el grupo de autores contemporáneos que apoyan esta tesis encontramos, por ejemplo, a SIRKS $S^{30}$.

minime decet. Nec enim sola pretii villotis querella contractus sine ulla culpa celebratus litigioso strepitu turbandus est". Traducción: "De ningún modo debe violarse la buena fe de una venta realizada sin la violencia del engaño, ya que un contrato celebrado sin culpa alguna, de ningún modo debe verse perturbado por el tumulto de un proceso, simplemente por el argumento de que el precio haya sido demasiado bajo".

c. Th. 3.1.7: Imppp. Gratianus, Valentinianus et Theodosius AAA. ad Remigio praefecto augustali: "Semel inter personas legitimas initus empti contractus est venditi ob minorem adnumeratam pretii quantitatem nequeat infirmari". Traducción: "Un contrato de compraventa, una vez celebrado entre personas autorizadas, no puede ser revocado por el hecho de que se ha pagado un precio demasiado bajo".

c. Th. 3.1.4: Imppp. Gratianus, Valentinianus et Theodosius AAA. ad Hypatium praefectum praetorio: "Quisquis maior aetate atque administrandis familiarum suarum curis idoneus comprobatus praedia etiam procul posita distraxerit, etiamsi praedii forte totius quolibet casu minime facta distractio est, repetitionis in reliquum pretii nomine vilioris copiam minime consequatur. Neque inanibus immorari sinatur objectis, ut vires sibimet locorum causetur incognitas, qui familiaris rei scire vires vel merita atque emolumenta debuerit". Traducción: "El que siendo mayor de edad y capaz de administrar su patrimonio haya vendido terrenos que se encuentren a gran distancia, inclusive si la venta se ha hecho por un precio muy bajo, no debe tener la facultad de pedir el excedente del precio con el argumento de que el precio recibido haya sido bajo".

27 Este autor, en su trabajo "Iustum pretium et iusta aestimatio", explica que las partes en que las leyes De rescindenda venditione aluden a la justicia del precio han de considerarse interpoladas. Esto, debido a que el justo precio sería un concepto ajeno a la mentalidad romana clásica y, por el contrario, sería un aditamento incorporado por la labor compiladora justinianea. Albertario (1921) pp. 4 y 5.

28 SOlAZZI (1921) p. 74.

29 Dekkers (1937) p. 15 y ss. En igual sentido, por ejemplo, De Zulueta (1966) p. 19.

30 SIRKS (1985) p. 307, y SIRKS (2007) p. 469. Para este autor, las dos frases finales en C.4.4.2 y 8 fueron agregadas por los compiladores justinianeos. 
Dentro del grupo de autores que niegan la existencia de interpolaciones, encontramos a LANDUCCI, VISKY ${ }^{31}$ y $\mathrm{HACKL}^{32}$. El primero de estos autores rebate de modo enérgico la opinión de GRADENWITZ, insistiendo en atribuir a DIOCLECIANO la paternidad del instituto y precisando que la falta de utilización de la regla contenida en los rescriptos por parte de los emperadores posteriores debe atribuirse, precisamente, al hecho de que se trataba de un duro golpe a la libertad negocial que operaba hasta ese momento sin mayores limitaciones. ${ }^{33}$

Adherimos a la doctrina de este último grupo de autores. Si, como explica Max KASER, la palabra interpolare significa "refrescar", "actualizar algo que se ha ido quedando viejo e inútil, para que valga como si fuera nuevo y sea útil otra vez" ${ }^{\prime \prime}$, ninguna interpolación genuina puede hallarse en estos textos. La acción de interpolar implica falsificar el texto original, presentándolo como una creación del autor a quien se le atribuye, en circunstancias que el autor de la obra original permanece en el anonimato ${ }^{35}$. Consideramos, pues, que JUSTINIANO no introduce innovaciones de importancia en los textos citados, más allá de meros retoques formales. Es por eso que a continuación, siguiendo a KASER, el foco de la crítica a los textos no se centrará en cuestiones de forma ${ }^{36}$, la que siempre podrá resultar engañosa al intérprete, sino más bien a su sustancia o contenido.

\section{CLASE DE OBJETOS A LOS QUE SE APLICA LA LAESIO ENORMIS}

La Ley Segunda comienza refiriéndose -en cuanto al objeto del contrato sujeto a una posible rescisión- a una cosa cualquiera, sin determinación de su naturaleza (simplemente una rem). Pero, acto seguido, emplea la frase "fundum venundatum", referida -en específico- a un inmueble.

La divergencia en torno al tipo de bienes -cosas, en general, versus inmuebles- proviene de la diferenciación entre la consulta efectuada por el

31 VISKY (1961) pp. 52-55, defiende la autenticidad de los rescriptos con el argumento de que, junto al edicto de precios, la laesio enormis constituye una medida adoptada por DIOCLECIANO para hacer frente a la crisis económica y la devaluación monetaria que sacudió al Imperio romano en el siglo III. En el mismo sentido, DupOnt (1972) p. 294.

32 HACKL (1981) p. 160.

33 Landucci (1916) p. 1200.

34 KASER (1998) p. 17.

35 Ídem, p. 19.

36 Una buena síntesis de las críticas de corte formal puede encontrarse en GARCíA (1962) p. 13. 
particular y la respuesta del Emperador. Del texto se desprende que este caso particular está referido, en concreto, a un inmueble y que la respuesta cubre un espectro mayor, al estar referida a una res. La interrogante principal que se plantea acá es si hubo alguna intencionalidad de parte de DıOCLECIANO, para a extender el ámbito de aplicación de la laesio enormis también a los bienes muebles.

Para LANDUCCI, la rescisión contemplada en los rescriptos sólo es aplicable a los inmuebles ${ }^{37}$. En cambio, VISKY ${ }^{38}$ y SolazzI ${ }^{39}$, han considerado viable extender el remedio a la venta de bienes muebles. Más tarde y en esta misma línea se ha manifestado D'ORS, pero con la diferencia de que atribuye esta extensión de la rescisión a las ventas de bienes muebles a la obra de comentaristas y legisladores medievales ${ }^{40}$.

En este ámbito, más allá de las razones de texto -que, en general, han sido la gran herramienta de la hipercrítica para acusar de interpolados a los rescriptos- también conviene explorar las razones de tipo económico. En este sentido, se ha dicho que el "aplicar la rescisión por lesión a la compraventa de cualquier objeto, fuera cual fuese su valor, sería un absurdo que no haría más que dificultar el tráfico jurídico, sería una medida desproporcionada para aplicar a cosas de poco valor o que puedan tener un precio muy variable (cosechas o ganado). Esta regla, en la práctica sólo tendría sentido y sería viable aplicándola a inmuebles, que por regla general tienen un precio elevado y por tanto sí que cabe hablar de lesión; por otro lado, tienen un precio más o menos estable y por tanto puede valorarse fácilmente el verdadero precio o su justo precio".$^{41}$

37 LANDUCCI (1916) pp. 1203 y 1204. Este autor compara la medida del edicto de precios de DIOCLECIANO con la laesio enormis y llega a la conclusión de que el primero se utilizó para regular las ventas de bienes muebles y la segunda para los inmuebles.

$38 \quad$ VISKY (1961) p. 55.

39 SolazZI (1921) p. 73.

40 En efecto, señala D'Ors (2004) pp. 581 y 582: “Esta rescisión por lesión enorme fue interpretada entre los comentaristas y legisladores medievales como una exigencia de la moral contractual $y$, en consecuencia, fue extendida a la venta de muebles y aun a favor del comprador, cuando se consideraba lesionado por haber pagado por encima de una mitad más del verdadero valor de la cosa comprada". Un argumento de texto que puede aportarse en apoyo a esta doctrina son los otros casos comprendidos en C.4.44, que incorporan como objetos de la venta únicamente a los inmuebles.

41 Montaña (1999) p. 56. 


\section{SUJETOS QUE RESULTAN BENEFICIADOS}

Los textos citados son claros para contestar esta interrogante: el beneficiado con la rescisión es el vendedor, mientras que al comprador se le otorga la facultad de, o consentir en la rescisión o pagar la diferencia faltante para completar el justo precio.

Una de las explicaciones dadas por la doctrina de por qué se restringe el privilegio de pedir la rescisión sólo al vendedor está en la existencia de una venta celebrada por una necesidad imperiosa de dinero, que conduce al afectado a contratar en condiciones desventajosas ${ }^{42}$. Algunos añaden, por la fecha de los rescriptos, que la causa específica de la rescisión contenida en ellos sería la de proteger a los pequeños terratenientes de las consecuencias de la crisis que sacudió al Imperio romano en el siglo III d.C. ${ }^{43}$

Dentro de las medidas tomadas por DıOCLECIANo para estabilizar la vida económica y resolver la crisis, encontramos la reforma monetaria del año 296 y el denominado edictum de pretiis rerum venalium del año 301, que le permitió fijar un precio máximo para la venta de ciertos bienes de consumo ${ }^{44}$.

42 Visky (1961) p. 63. En igual sentido, ZiMMERMANN (1990) p. 261.

43 VISKY (1961) p. 61, y ZIMMERMANN (1990) p. 261.

En apoyo a la teoría expuesta puede citarse la información aportada por el historiador APIANO, quien afirma que, una vez que los ricos ocuparon la mayoría de la tierra no repartida [por la reforma agraria graquiana] "y convencidos de que con el transcurso del tiempo nadie se las arrebataría, ocuparon las fincas contiguas a las suyas y las parcelas menores de los pobres, en parte comprándolas por la fuerza, cultivando no ya campos sino latifundios [...]. Esta posesión les daba grandes beneficios a causa de la proliferación de esclavos, que aumentaban al estar exentos de la milicia. Por tales razones, los poderosos se enriquecieron desmesuradamente y el género de los esclavos llenó las tierras". Esto, unido a otros factores, se transformó en un grave problema social, tal como lo demuestran los acontecimientos de esa época y las luchas políticas que se fueron gestando. De Martino (1985) pp. 147, 148 y 150. Para Capogrosi (2007) p. 351, la mencionada crisis tuvo como fundamento último la jamás superada contradicción entre la expansión de la economía esclavista y el crecimiento o, al menos, la estabilidad de la fuerza productiva necesaria para afrontar el desarrollo posterior. Así, una vez que el imperio llega a su máxima extensión, ya no pudo hacer uso del superávit de esclavos que trajeron consigo las guerras de conquista.

44 Un panorama global de la economía de la época nos es dado por GARCíA GARRIDO, quien explica que: "Las actividades comerciales y financieras de la época del Bajo Imperio se encuadran en la gran crisis económica y social del mundo romano. El dirigismo económico y el intervencionismo de los poderes públicos limitan la actividad financiera de 
Si bien algunos autores han vinculado al edicto con la lesión enorme -en cuanto serían instrumentos complementarios de protección a los pequeños terratenientes ${ }^{45}$, cualquiera sea la opinión que se adopte al respecto, ésta deberá considerar que la medida constituida por el edicto no afectaba la eficacia de la compraventa que la infringiera, ya que sólo se limitaba a establecer penas para ciertos $\operatorname{casos}^{46}$.

Si se postula a la necesidad como criterio de aplicación del instituto, tiene sentido que sólo resulte beneficiado el vendedor, ya que es difícil concebir la compra de un inmueble por necesidad. Se compran por tal motivo los objetos necesarios para la subsistencia, como los víveres, la vestimenta o los medicamentos, pero no los predios. En consecuencia, sí resulta coherente pensar que alguien venda un inmueble apremiado por necesidades que sólo podrá satisfacer con el dinero obtenido de la celebración de ese contrato.

En contra de las opiniones anteriores encontramos la de SIRKS, quien considera que la crisis aludida no es de tal magnitud para justificar la aparición de la laesio enormis. Esta última no sería, por tanto, una respuesta a una crisis, sino una clase especial de restitutio in integrum que tiene la

los banqueros y agentes privados. Para conseguir una estabilidad económica cada vez más precaria, los emperadores acuden al control de las monedas y a intervenir el precio de las mercancías y servicios. Ejemplo de ello es la famosa ley de tasas de Diocleciano (edictum de pretiis rerum venalium), que fijaba los precios de las mercancías desde los artículos de primera necesidad hasta los de lujo, y en los servicios desde los salarios de los obreros hasta los honorarios de médicos y abogados [...]. Los emperadores, sin embargo, no daban ejemplo con sus medidas intervencionistas. Desde la época de Caracalla los emperadores falsean las monedas, acuñándolas con un peso inferior al legal, o incluso ahuecando las de oro para rellenarlas con metales de baja calidad. El atesoramiento de las auténticas monedas por los particulares, para evitar la rapacidad del Fisco o para sustraerlas del latrocinio de los soldados, contribuyó a una subida extraordinaria de los precios y a una incontrolable inflación". García (2001) p. 43. En igual sentido, vid. GonZÁLEZ (2011) pp. 129-138. En cuanto a la inflación, SIRKS (2007) pp. 466 y 469, la descarta categóricamente como causa de la laesio enormis.

45 Es la opinión de VISKY (1961) pp. 49-52, quien considera que la laesio enormis y el edicto de precios son medidas tomadas por el imperio para hacer frente a la crisis económica de esa época. En la misma línea, Scıuto (2000) p. 422, agrega que, en orden cronológico, la primera gran medida introducida por DIOCLECIANO para paliar la crisis habría sido la introducción de la laesio ultra dimidium.

46 Guzmán (1996) p. 137. En igual sentido se pronuncian Álvarez y De Aymerich (1989) p. 19, quienes agregan que la tarificación de los precios es contingente por su naturaleza, mientras que la rescisión por lesión es un remedio contractual, de por sí constante. 
particularidad de otorgar al comprador la elección de rescindir el contrato o pagar la diferencia ${ }^{47}$.

Finalmente, otras teorías de corte ecléctico han considerado que el fundamento de la rescisión está en un conjunto de condicionantes, no sólo en razones económicas y sociales ${ }^{48}$.

En cuanto a esta dificultad para encontrar los motivos que se tuvo en mente para otorgar el beneficio solamente al vendedor, WATSON ha advertido que los estudiosos del tema se enfrentan a un círculo vicioso: si no se conocen las causas que motivaron el nacimiento de la rescisión por lesión, no se puede precisar su ámbito de aplicación; pero si se desconoce su alcance, no se pueden descubrir sus causas ${ }^{49}$.

\section{TIPOS DE CONTRATOS A LOS QUE SE APLICA LA RESCISIÓN POR LESIÓN}

En esta materia, la doctrina está prácticamente conteste en que la rescisión por lesión de la lex Secunda es sólo aplicable a la compraventa. El único autor que manifiesta opinión en contrario es Solazzı, quien aboga por ampliar el ámbito de aplicación a todos los contratos onerosos ${ }^{50}$.

Pese a su originalidad, la tesis de Solazzı parece forzada si se considera que la rescisión se presenta -en el contexto romano- como un beneficio otorgado con carácter excepcional y sólo al contrato de compraventa. Así, C.4.44 se refiere con claridad a las Leyes De rescindenda venditione, aludiendo directa y únicamente al contrato de venta. En apoyo a este punto se suman también los argumentos de SIRKS, quien considera que la laesio enormis es un tipo especial de restitutio in integrum, restringido de manera exclusiva a las compraventas celebradas por mayores de veinticinco años. Es por esta razón que el rescripto fue ubicado en el título De rescindenda venditione y no en el título de restitutio in integrum para mayores de edad ${ }^{51}$. Ubicarla en este

SIRKS (1985) p. 299, y SIRKS (2007) p. 469.

48 En este grupo encontramos, por ejemplo, a HACKL (1981) pp. 147 y ss., para quien el fundamento histórico del instituto no se basa sólo en condicionamientos económicos, sino también ético-jurídicos. En igual sentido, ABRIL (2003) p. 21.

49 Watson (1981) p. 192.

$50 \quad$ Este autor se basa en C.2.20.5, C.5.18.6 y C.3.38.3 para extender el ámbito de aplicación de la rescisión por lesión. Solazzi (1921) p. 57.

51 SIRKS (1985) pp. 301 y 302. 
WALKER SILVA, NATHALIE (2017): LAS LEYES DE RESCINDENDA VENDITIONE Y LA CONFIGURACIÓN ORIGINARIA DE LA RESCISIÓN DEL CONTRATO POR LESIÓN ENORME.

último título habría implicado extender el beneficio a hipótesis de negocios distintas de la compraventa, cosa que no ocurrió.

\section{FORMA PROCESAL DE HACER VALER LA RESCISIÓN}

La ley Segunda y Octava nada expresan acerca del procedimiento para obtener la rescisión de la venta. La lex Secunda sólo alude a una auctoritate judicis intercedente, pero no señala la forma precisa en que el juez debe intervenir. Al respecto, algunos consideran que el procedimiento aplicable era la cognitio extraordinem, porque era el modo de litigación de la época justinianea ${ }^{52}$. Otros, en cambio, piensan que si el comprador no optaba por la vía de completar el justo precio, la solicitud se tramitaba como una restitutio in integrum ${ }^{53}$.

Sin perjuicio de la estrecha relación histórica que une a la restitutio in integrum con la rescissio, hay autores que han ampliado el enfoque de estudio del problema de la ineficacia de actos válidamente celebrados, vinculando a la rescisión también con la buena fe. Es el caso de Sciuto, para quien el encuadramiento sistemático de la laesio enormis dado por los compiladores justinianeos esclarece no sólo la naturaleza jurídica del instituto, sino también su tutela procesal. Esto, porque bajo la rúbrica De rescindenda venditione se agruparon una serie de casos en que, gracias al principio de buena fe contractual, se hizo posible rescindir ventas que eran formalmente perfectas ${ }^{54}$. De manera que se estableció el principio de que un contrato de compraventa jurídicamente perfecto no puede ser privado de valor, a menos que la buena fe que debe existir entre las partes sea violentada. Por ende, elementos como el dolo o la fuerza -y, bajo la óptica compilatoria, también la lesión ultra dimidium- constituyen una violación del principio de la buena fe ${ }^{55}$. Así, para SCIUTO, si se considera la naturaleza del contrato de compraventa consensual como sinónimo de contrato que lleva siempre incorporada la buena fe en su fundamento jurídico, no se podría excluir que el medio procesal utilizado para rescindir la venta haya sido precisamente la actio venditi, conforme al iudicium bona fidei del proceso formulario, oportunamente adaptado al sistema de la cognitio extraordinem ${ }^{56}$.

\footnotetext{
52 Así piensa, por ejemplo, Brassloff (1912), p. 263.

$53 \quad$ SIRKS (1985) p. 306.

$54 \quad$ SCIUTO (2000) p. 428.

55 ĺdem., pp. 428 y 429.

56 SCIuto (2000) p. 431; en sentido similar, DemOntés (1924) pp. 14 y 15, y VaCCA (1997) p. 128. La diferencia fundamental entre los contratos de Derecho estricto (amparados por iudicia stricti iuris) y los contratos de buena fe (protegidos por bona fidei iudicia) es que la cláusula ex fide bona, propia de estos últimos, permite al juez gran libertad de aprecia-
} 
En la misma línea de la buena fe, encontramos también la opinión de Zıııотто. Para esta autora, en el título De rescindenda venditione:

"la buena fe aparece como un criterio de juicio unitario, en base al cual son valorados diversos momentos o aspectos de la actividad negocial; es decir, por un lado, el comportamiento de los contratantes y, por otro lado, el contenido del negocio. De tal modo que, cuando el juicio de buena fe tiene por objeto el comportamiento de las partes, se considera la calidad de éstas. Contrario a la buena fe será, entonces, el comportamiento incorrecto y el contrato será inválido por las causales de violencia o dolo. En cambio, cuando el juicio de buena fe tenga por objeto el contenido del contrato, es decir, la reglamentación de intereses, se considerará sólo la medida del intercambio. Contrario a la buena fe será, en tal caso, el acuerdo que contenga un desequilibrio inaceptable entre las prestaciones, superior a los límites inherentes a la realidad de la contratación y a la estructura del mercado" ${ }^{\prime 27}$.

Para ZıııotTo, respecto de este último juicio, es claro que el límite que establecieron los compiladores justinianeos contribuyó a disminuir la relevancia de situaciones subjetivas relacionadas con la calidad de las partes y, por tanto, a dar menor cabida a la arbitrariedad, al aportar una medida precisa y clara, que oficia también de garantía de la libertad y la autonomía ${ }^{58}$.

\section{LA REFERENCIA A LAS RAZONES DE JUSTICIA Y EQUIDAD}

Dentro de las numerosas interrogantes que plantean los rescriptos en comento se encuentran aquellas que apuntan a su genuino contenido. En este ámbito, una de las frases que más concita el interés de los autores es la que apela a razones de humanidad ("humanum est") para solucionar el problema planteado por el tal Aurelio Lupo a DioCLECIANO. Se ha dicho que esa clase de razones - de tipo humanitario o de equidad- no son propias de la época en que se han fechado los rescriptos -ni menos de la época clásica-, sino que de los tiempos de JustinianO ${ }^{59}$. Así, tales expresiones no se condecirían ni con

ción, al poder tomar en cuenta el criterio de la lealtad en las convenciones (bona fides). Grosso (1963) p. 235, y MiQuel (1992) p. 302.

57 Zіціотто (2007) p. 627.

58 Ídem., pp. 627 y 628.

59 Quien primero desliza esta hipótesis es el propio Thomasius (1730) en su De aequitate cerebrina, donde expresa: "His suppositis probabile est, Tribonianus has leges Diocleciani deprehendisse in Codice Gregoriano et Hermogeniano [...]". Thomasius sugiere que los 
el léxico jurídico ni con el filosófico empleado en aquel tiempo. Para esta doctrina, dentro de las causas que habrían influido en la creación aportada por JUSTINIANO, una primera estaría dada por una nueva corriente filosóficoreligiosa que, basada en principios éticos, habría propugnado la instauración de principios de equidad y justicia conmutativa en las relaciones contractua$l_{e}{ }^{60}$. En tanto una segunda causa se encontraría en la necesidad de poner fin a los abusos experimentados por los pequeños propietarios, que vendían sus inmuebles a bajos precios compelidos por necesidades económicas ${ }^{61}$.

En cuanto al supuesto origen romano clásico de la rescisión por lesión enorme, nos pronunciamos por la negativa ${ }^{62}$. Al respecto, si bien existen en la Roma clásica algunos indicios de la aplicación práctica de criterios de equidad para dejar sin efecto los contratos, el principio de equidad y conmutatividad inserto en la rescisión por lesión enorme sólo se origina en el Corpus luris Civilis. De tal modo que en la época clásica no podían dejarse sin efecto las compraventas por puras desigualdades en el precio y sólo se admitía ese remedio en ciertos casos de simulación, fraude al Estado o a las leyes ${ }^{63}$. por eso,

compiladores justinianeos habrían tomado los rescriptos que contienen la laesio enormis de los códigos Gregoriano y Hermogeniano. Esta opinión es hoy compartida por HonORÉ (1994) pp. 139 y ss. También Albertario (1921) pp. 18 y 19, considera que las leyes De rescindenda venditione son obra de las interpolaciones efectuadas por JustinIANO.

60 Álvarez y De Aymerich (1989) p. 19.

${ }^{61}$ Ibídem. Como puede verse, es el mismo argumento empleado por quienes atribuyen la autoría de los rescriptos a DiocLECIANO, sólo que acá se reitera la causa que daría origen al instituto, pero trasladándola a una época posterior.

62 Pero no por el recurso a las razones humanitarias. Tal como ha demostrado Honoré (1994) p. 100, éstas sí tenían lugar en la época clásica. En su estudio sobre los derechos humanos en ULPIANO, destaca que la humanidad es un valor al que ULPIANO apela, especialmente cuando está en juego la libertad. Así, en este punto, concordamos con HONORÉ, ya que nuestra negativa a admitir la rescisión por lesión en la época clásica no está dada por el concepto de humanidad empleado en los rescriptos, sino por las diversas y cambiantes soluciones que se dieron en esa época en torno a la rescisión.

63 Así, por ejemplo: "Idem Pomponius ait de pretio emtionis et venditionis naturaliter licere contrahentibus se circumvenire" (D.4,4 de min. 16,4). Trad.: "El mismo Pomponio dice que en el precio de la compraventa es naturalmente lícito a los contratantes engañarse". En igual sentido: "Quemadmodum in emendo et vendendo naturaliter concessum est, quod pluris sit, minoris emere, quod minoris sit, pluris vendere et ita invicem se circumscribere, ita in locationibus quoque et condictionibus locus est: et ideo praetextu minoris pensionis locatione facta, si nullus dolus adversarii probari possit, rescindi locatio non potest" (D.19.2.22.3 y 19.2.23). Traducción: "Así como en el comprar y vender está naturalmente permitido comprar por menos lo que valga más, y vender por más lo que valga menos $y$, 
si bien en el Derecho romano clásico existían ciertos casos en que el Derecho amparaba la equidad en los contratos -como ocurre, por ejemplo, con las restitutiones in integrum $-{ }^{64}$, consideramos que resulta infructuosa la búsqueda de supuestos principios generales de amparo a la justicia conmutativa en los

de este modo, engañarse mutuamente, así también esto tiene lugar en las locaciones y conducciones; y, por esto, no puede rescindirse la locación so pretexto de haberse hecho la locación por menos renta, si no pudiera probarse dolo alguno del adversario". GARCíA (1889), p. 959. Los textos anteriores ratifican que resulta completamente lícito a las partes tratar de obtener el precio que les sea más ventajoso. Tanto es así que el Título del Digesto, que trata sobre la rescisión de la venta [D.18, 5: "De rescindenda venditione et quanto licet ab emptione discedere"], no contiene ninguna referencia a la lesión. García (1962) p. 15.

64 Otros dos ejemplos, en tal sentido, son: D.18,1,38 (Ulpianus libro septimo disputationum): "Si quis donationis causa minoris vendat, venditio valet; toties enim dicimus in totum venditionem non valere, quoties universa venditio donationis causa facta est: quoties vero viliore pretio res donationis causa distrahitur, dubium non est venditionem valere. Hoc inter ceteros, inter virum vero et uxorem donationis causa venditio facta pretio viliore nullius momenti est" (Traducción: "Si alguno vende en menor precio, con intención de donar, vale la venta, pues decimos que la venta es totalmente inválida sólo cuando haya sido hecha enteramente por causa de donación, pero cuando se enajene una cosa en un precio más bajo por causa de donación, no hay duda que la venta vale. Esto, siendo entre extraños, porque entre marido y mujer la venta hecha con finalidad de donación, en un precio más bajo, no tiene validez"). García (1889), p. 896. Traducción: Digesto de Justiniano (1968), p. 664. Y D.24,1,5,5 (Ulpianus libro trigesimo secundo ad Sabinum): "Circa venditionem quoque Iulianus quidem minoris factam venditionem nullius esse momenti ait; Neratius autem, cuius opinionem Pomponius non improbat, venditionem donationis causa inter virum et uxorem factam nullius esse momenti, si modo, cum animum maritus vendendi non haberet, idcirco venditionem commentarius sit, ut donaret; enimvero si, quum animum vendendi haberet, ex pretio ei remisit, venditionem quidem valere, remissionem autem hactenus non valere, quatenus facta est locupletior. Itaque si res quindecum veniit quinque, nunc autem sit decem, quinque tantum praestanda sunt, quia un hoc locupletior videtur facta" (Traducción: "Respecto de una venta, dice también Juliano que es ciertamente de ningún valor la venta hecha por menor precio; en cambio, Neracio -cuya opinión no desaprueba Pomponio- sostiene que la venta hecha entre marido y mujer por causa de donación es de ningún valor si no teniendo el marido intención de vender hubiera imaginado la venta para esto, para hacer la donación; pero que si teniendo ánimo de vender, le rebajó el precio, es ciertamente válida la venta, pero no es válida la rebaja en cuanto ella se hizo más rica. Y así, si una cosa que valía quince fue vendida por cinco, pero ahora valiera diez, se habrán de entregar solamente cinco, porque en esto se considera que se hizo más rica"). García (1892) pp. 161 y 162. En ambos textos de ULPIANO se exige la necesidad de un justo precio en la compraventa, siempre que ésta pueda consista en un negocio simulado entre marido y mujer, burlando la prohibición de efectuarse los esposos donaciones entre sí. MontAÑa (1999) p. 27. 
contratos, habida cuenta del carácter casuístico de las soluciones dadas por los juristas de la Roma de aquella época.

Es en el Derecho postclásico en donde las fuentes dan cuenta de los rescriptos 2 y 8 , De Rescindenda venditione ${ }^{65}$. Pero, en nuestro concepto, ese único antecedente no es suficiente para sustentar una teoría sobre la lesión enorme. Sobre todo porque, como hemos visto, hay un grupo importante de rescriptos posteriores -incluso de los propios emperadores DıOCLECIANO y MAXIMIANO- ${ }^{66}$ que niegan la posibilidad de alegaciones fundadas sólo en la injusticia del precio. Es así como, en algunos casos, agregan como causa necesaria de la rescisión la existencia de un vicio del consentimiento.

Producto de lo anterior, consideramos que el principio sancionador de la lesión enorme no se asienta ni siquiera en la Roma postclásica, sino que es una labor posterior, fruto del pensamiento cristiano $^{67}$. Dicha labor se inicia verdaderamente con JUstiniano -en el Corpus luris Civilis ${ }^{68}$, cuerpo legal que amplía el rango de aplicación de los textos más allá de los casos particulares de los rescriptos- y va poco a poco extendiéndose bajo el amparo de la fe cristiana, con las doctrinas sobre el justo precio y la justicia conmutativa que debe reinar en los contratos ${ }^{69}$. Tales ideas de moral y justicia terminan de cristalizar en la Edad Media -por el influjo de los glosadores, postglosadores

65 Para PARRA (2008) p. 17, la excepcionalidad del instituto radica en que encuentra su última ratio en la expresión "humanum est", de influencia cristiana y que impone un deber universal fundamentado en la justicia y la equidad. Tal humanización es atribuida por la autora a DIOCLECIANO.

66 Véase, por ejemplo, C.4.44,4 Impp. Diocletianus et Maximianus AA. et CC. Sempronio Euxodio. Sobre este punto, PARDo (1966) p. 17, opina que el hecho de que Diocleciano y sus sucesores hayan resuelto en contra de solicitudes como la de Aurelio Lupo confirma aún más la teoría de las interpolaciones.

67 Seguimos aquí a GHIRARDI y FilipPI (2009) p. 7. Para estos autores, si aceptamos que los textos de C.44.2 y C.4.44.8 están interpolados, tendremos que admitir también que la lesión no tiene su origen en Roma, sino en la Constantinopla o Bizancio de Justiniano, desarrollándose y adquiriendo su caracterización definitiva en la Edad Media tardía. Vid., por todos, PARDO (1966) p. 17. En contra, PARRA (2008), p. 15, para quien el origen del instituto se encuentra en Diocleciano, aunque comparte la idea de que es un instrumento al servicio de la socialización y humanización del Derecho.

69 En este mismo sentido se pronuncia ParDo (1966) p. 17, quien señala que: "Son las doctrinas cristianas las que inspiraron el establecimiento de la institución. El emperador JusTINIANO, tomando como base el rescripto de DIOCLECIANO "Repetitio in reliquum pretii nomini valoris", amplió dicha acción que sólo permitía al vendedor obtener un complemento del precio, en el sentido de establecer una verdadera acción rescisoria, consagrando a favor del comprador la opción de permitir [léase: allanarse a] la rescisión, o completar el precio". 
y canonistas-, asentándose de manera definitiva en la Edad Moderna. Desde ahí, pasarán al fenómeno codificador transformándose en Derecho positivo, vigente en varios países del mundo cristiano.

\section{CONCLUSIONES}

Las fuentes romanas en materia de compraventa e ineficacia de los contratos no nos permiten reconocer una teoría de la rescisión con bases sólidas, sino que, al contrario, conforman casos aislados y contradictorios entre sí. Por consiguiente, el genuino principio sancionador de la lesión enorme recién comienza a perfilarse en la obra justinianea, gracias a la generalización del contenido de los textos recogidos en la rúbrica de rescindenda venditione ${ }^{70}$. De tal manera que el Corpus luris no se limita a recoger una teoría suficientemente perfilada y autónoma, sino que su concreto aporte es el de haber sentado las bases para una posterior expansión y perfeccionamiento de la doctrina incorporada en el Codex, que irá de la mano del concepto medieval de laesio enormis.

\section{BIBLIOGRAFÍA CITADA}

ABRIL, Juan (2003): La rescisión del contrato por lesión -Enfoque doctrinal y jurisprudencial- (Valencia, Tirant lo Blanch).

Albertario, Emilio (1921): "Iustum pretium e iusta aestimatio", Bullettino dell'Istituto di Diritto Romano (BIDR), vol XXXI: pp. 1-19.

Álvarez, Rafael y AYMERICH, Regina de (1989): La rescisión por lesión en el Derecho Civil español común y foral (Granada, Comares).

Amunátegul, Carlos (2011): Historia social, política y jurídica de Roma (Santiago, Editorial Abeledo Perrot).

Aquino, Tomás de (2008): Tratado de la ley, Tratado de la justicia, Opúsculo sobre el gobierno de los Príncipes (Trad. de Carlos González, 9a edición, México D.F., Editorial Porrúa).

70 En igual sentido, Mirabelu (1951) p. 15, y Grebieniow (2014) p. 198. Para este último autor, la diferencia más grande que existe entre la configuración de la laesio enormis en la legislación de Diocleciano y la de Justiniano, es que la segunda la concibió con una validez general, dejando de lado los límites inherentes a los rescriptos. Con posterioridad, la jurisprudencia medieval y moderna la ha generalizado en cuanto al objeto de reglamentación, aplicando la laesio enormis a otros contratos sinalagmáticos y extendiendo la aplicación del remedio a la contraparte. 
BRASSLOFF, Stephan (1912): "Zur Lehre von der laesio enormis im byzantinischen Recht", Zeitschrift für Vergleichende Rechtswissenschaft, vol. 27: pp. 261-272.

Bueno, Juan (2013): "Los rescriptos imperiales como fuente del Derecho", Revista Internacional de Derecho Romano, no 11: pp. 378-434.

Burke, Edmund (1830): An historical essay on the laws and the goverment of Rome ( $2^{\mathrm{a}}$ edición revisada, Cambridge, T. Stevenson).

Martino, Francesco de (1985): Historia económica de la Roma antigua (Trad. de Esther Benítez, Madrid, Akal).

Capogrosi, Luigi (2007): Diritto e potere nella storia di Roma (Napoli, Jovene Editore).

Ciapparoni, Fabrizio (1968): "Voz rescritto. Diritto Romano", Azara y Eula (dirs.) XV Novissimo Digesto Italiano (Torino, Vnione Tipografico- Edictrice Torinese) pp. 587-588.

Codex TheOdosianus (1905): Libri XVI cvm constitvtionibvs sirmondianis et leges novellae ad Theodosianvm pertinentes, vol. I, parte posterior (Edición de Theodor Mommsen y Paulus M. Meyer, Berlín, Weidmannos).

Corpus Iuris Civilis cum glossis AcCursil (2006): Tomo IV (Frankfurt am main, Vico Verlag).

Chamie, José (2010): "Rescisión por lesión enorme: el problema del origen", Revista de Derecho Privado, no 19: pp. 5-40.

D'Ors, Javier (2004): Derecho Privado Romano (10 edición revisada, Pamplona, EUNSA Ediciones Universidad de Navarra).

De Zulueta, Francis (1966): The Roman Law of Sale (Reimpresión de la $1^{\text {a }}$ edición de 1945, Oxford, Oxford University Press).

DekKers, René (1937): La lésion énorme. Introduction a l'histoire des sources du Droit (Paris, Librairie du Recueil Sirey).

Demontés, Emile (1924): De la lésion dans les contrats entre majeurs. Etude de droit positif et de législation comparée (Paris, Librairié Générale de Droit et de Jurisprudence). 
Digesto de Justiniano (1968): Tomo I. Constituciones Preliminares y Libros 1-19 (Trad. Álvaro D’Ors, F. Hernández-Tejero, P. Fuenteseca, M. García Garrido y J. Burillo, Navarra, Aranzadi).

Dupont, Clémence (1972): "La vente et les conditions socio-économiques dans l'empire romain de 312 à 535 après Jésus-Crist", Revue Internationale des droits del'antiquité, vol. XIX n³ : pp. 275-310.

García, Ildefonso (1889): Cuerpo del Derecho Civil Romano, Tomo I, Primera Parte (Instituta-Digesto) (Barcelona, Jaime Molinas, Editor).

(1892): Cuerpo del Derecho Civil Romano Tomo II, Primera Parte (Digesto) (Barcelona Jaime Molinas, Editor).

García, Manuel (2001): El comercio, los negocios y las finanzas en el mundo romano (Madrid, Fundación de Estudios Romanos).

García, Ricardo (1962): Rescisión por laesio ultradimidium (Barcelona, Bosch)

GhirardI, Juan y FilıPPI, Cristina (2009). "La laesio ultradimidium", Revista General de Derecho Romano, no 13: pp. 1-22.

GIRARD, Paul (1929): Manuel élémentaire de Droit Romain (Paris, Librairie Arthur Rousseau et Cie. Éditeurs, huitième édition revue et mise a jour par Félix Senn).

GonZÁlez, Alberto (2011): "La inflación en el imperio romano de Diocleciano a Teodosio", Documenta et Instrumenta, vol. 9: pp. 123-152.

Gradenwitz, Otto (1889): "Interpolatione e interpretatione", Bullettino dell'Istituto di Diritto Romano (BIDR), pp. 3-15.

GreBienIOW, Aleksander (2014): "La laesio enormis e la stabilitá contrattuale", Revue internationale des droits de l'antiquité, vol. 61: pp. 195-216.

Grosso, Giusseppe (1963): I/ Sistema romano del contratti (3ª edición, Torino, G. Giappichelli, Editore).

Guzmán, Alejandro (1996): II Derecho Privado Romano (Santiago, Editorial Jurídica de Chile). 
HACKL, Karl (1981): "Zu den Wurzeln der Anfechtung wegen laesio enormis", Zeitschrift der Savigny-Stiftung für Rechtsgeschichte, vol. 98: pp. 147-161.

Honoré, Tony (1994): Emperors and Lawyers (2a edición, Oxford, Clarendon Press-Oxford).

(2004): "How Tribonian organised the compilation of Justinians Digest", Zeitschrift der Savigny-Stiftung für Rechtsgeschichte, vol. 121: pp.1-43.

KASER, Max (1998): Las interpolaciones en las fuentes jurídicas romanas (Trad. al castellano de José María Coma y Götz Gallenkamp, Granada, Comares).

KunKeL, Wolfgang (1972): Historia del Derecho Romano (Trad. de la $4^{a}$ edición alemana por Juan Miquel, Barcelona, Ediciones Ariel).

LANDUCCI, Lando (1916): La lesione enorme nella compra e vendita. Essame storico-critico d'una rinnovata proposta di intepolazione giustineanee (Venezia, Premiate officine grafiche di Carlo Ferrari).

MARTín, José (1995): La rescisión del contrato. En torno a la lesión contractual y el fraude a los acreedores (Barcelona, José María Bosch, Editor).

Miquel, Joan (1992): Derecho Privado Romano (Madrid, Marcial Pons, Ediciones Jurídicas S.A.).

Mirabell, Giuseppe (1951): La rescissione del contratto (Napoli, Casa Edictrice Dott. Eugenio Jovene).

MONTAÑA, Amparo (1999): La rescisión por lesión (origen, evolución histórica y recepción en Derecho moderno) (Valencia, Tirant Lo Blanch).

PARDO, Rafael (1966): Introducción a la teoría de la lesión enorme (Tesis de Grado para optar al título de Doctor en Ciencias Jurídicas en la Facultad de Derecho y Ciencias Socio-Económicas de la Pontifica Universidad Javeriana, Bogotá, Editora El Diario).

PARRA, María (2008): "La rescisión del contrato en los rescriptos de Diocleciano. C. 4. 44. De rescindenda venditione. La laesio ultra dimidium", Revista General de Derecho Romano, no 11: pp. 1-20. 
RASCÓN, César (1998): "Sobre la recepción de la laesio ultradimidiam como causa de rescisión de los contratos en el Derecho español", DíAz, Antonio, Pérez, Trinidad; Robles, Juan y Botella, Carmen (coords.), Actas del II Congreso Iberoamericano de Derecho Romano (Murcia Universidad de Murcia, Servicio de Publicaciones) pp. 135-157.

SAmper, Francisco (2007): Derecho Romano (2ª edición, Santiago, Ediciones Universidad Católica de Chile).

Sciuto, Patricia (2000): "Sulla c.d. rescissione per lesione enorme", Labeo, vol. 46, no 3: pp. 404-433.

SIRKS, Adriaan (1985): "La laesio enormis en Droit Romain et Byzantin", Tijdschrift voor Rechtsgeschiedenis/Revue dHistoire du droit/thelegal history Review, vol. 53, n³: pp. 291-307.

(2007): "Laesio enormis again", Revue Internationale des droits de l'antiquité, vol. LIV: pp. 461-469.

SolazzI, Siro (1921): "L'origine storica della rescisione per lesione enorme", Bullettino dell'Istituto di Diritto Romano (BIDR), vol. XXXI: pp. 51-87.

Thomasius, Christian (1730): Dissertatio juridica inauguralis, de aequitate cerebrina L. II. C. De rescind. vendit. et ejus usu practico (Halae Magdeburgicae, Literis Salfedianis).

VACCA, Letizia (1997): "Buona fede e sinallagma contrattuale", Rivista Internazionale di Diritto Romano e Antico (IVRA), vol. XLVIII: pp. 125-144.

VISKY, Károly (1961): "Appunti sulla origine della lesione enorme", IVRA. Rivista Internationale di Diritto Romano e Antico, vol. XII, Parte Prima: pp. 40- 64 .

Watson, Alan (1981): "The hidden origins of enorm lesion", The Journal of Legal History (London, Routledge), pp.186-193.

ZıııOTto, Paola (2007): "La misura della sinallagmaticità: buona fede e laesio enorme", en Garofalo (ed.), La compravendita e l'interdipendenza delle obligationi nel Diritto Romano (Padova, Cedam), pp. 598-628. 
WALKER SILVA, NATHALIE (2017): LAS LEYES DE RESCINDENDA VENDITIONE Y LA CONFIGURACIÓN ORIGINARIA DE LA RESCISIÓN DEL CONTRATO POR LESIÓN ENORME.

ZimMERMANN, Reinhard (1990): The Law of obligations. Roman foundations of the civilian tradition (Cape Town-Wetton-Johannesburg, Juta \& Co. Ltd., first edition).

(2010): Derecho Romano, Derecho Contemporáneo, Derecho Europeo. La tradición del Derecho Civil en la actualidad (Trad. de Javier M. Rodríguez Olmos, Bogotá, Publicaciones de la Universidad Externado de Colombia). 